\title{
Joseph Delaville-Leroulx (1747-1803) : entre négoce et politique ou la carrière du premier parlementaire lorientais
}

Joseph Delaville-Leroulx (1747-1803): between trade and politics or the career of the first Lorient parliamentarian

\section{Gérard Le Bouëdec}

\section{(2) OpenEdition}

Journals

\section{Édition électronique}

URL : http://journals.openedition.org/abpo/3668

DOI : $10.4000 / a b p o .3668$

ISBN : 978-2-7535-6497-8

ISSN : 2108-6443

Éditeur

Presses universitaires de Rennes

Édition imprimée

Date de publication : 30 juin 2017

Pagination : 75-99

ISBN : 978-2-7535-6495-4

ISSN : 0399-0826

Référence électronique

Gérard Le Bouëdec, « Joseph Delaville-Leroulx (1747-1803) : entre négoce et politique ou la carrière du premier parlementaire lorientais ", Annales de Bretagne et des Pays de l'Ouest [En ligne], 124-2 | 2017, mis en ligne le 17 juillet 2019, consulté le 02 janvier 2020. URL : http://journals.openedition.org/abpo/ 3668 ; DOI : 10.4000/abpo.3668 


\title{
Joseph Delaville-Leroulx (1747-1803) : entre négoce et politique, ou la carrière du premier parlementaire lorientais
}

\author{
Gérard LE BOUËDEC \\ Professeur émérite d'histoire maritime, université de Bretagne Sud, UMR CERHIO
}

L'origine de cet article plonge dans le bouillonnement des recherches entreprises lors du bicentenaire de la Révolution par le comité historique de Lorient. Les deux registres ${ }^{1}$ contenant les 195 lettres écrites par Joseph Delaville-Leroulx, le député de Lorient, et les courriers qui lui étaient adressés par le bureau de correspondance de la ville constituaient une source de choix pour plusieurs publications ${ }^{2}$. Edna Lemay y trouva des informations pour son dictionnaire biographique des constituants ${ }^{3}$. J'y puisai moi-même d'abord avec Jacques Soteras, une large partie des connaissances nécessaires pour un livre sur l'année 1789 à Lorient et ensuite pour une communication au colloque de Grenoble consacrée aux origines provinciales de la Révolution ${ }^{4}$. Malheureusement, la publication de l'ensemble de la correspondance ne put être menée à bien. La mobilisation de nombreux chercheurs permit de dépouiller diverses sources et notamment les séries L 1075 et L 1080 des archives départementales du Morbihan, largement mises à contribution. Puis le dossier accumulé resta en sommeil jusqu'en 2001. René Estienne, conservateur du Service Historique de la Défense à Lorient, avait acquis un fonds Delaville-Leroulx comprenant les papiers de

1. Archives municipales de Lorient. Registres de correspondances du 30 avril 1789 au 25 août 1790 , BB12 et 13 .

2. Arch. mun. de Lorient. Correspondance de Joseph Delaville-Leroulx, BB 12-156 (30 avril 1789-9 août 1789) et BB 13-158 (12 août 1789-25 août 1790), (au verso copies des lettres reçues, au recto copies des réponses apportées par le bureau de correspondance).

3. Lemay, Edna, Dictionnaire des Constituants, 1789-1791, t. 1, Paris, Librairie du Bicentenaire, 1991.

4. LE BOUËDEC, Gérard, SOTERAS, Jacques, L'année 1789 dans le pays de Lorient, Lorient, Comité historique du bicentenaire, 1988; LE BouËDEc, Gérard, « Delaville Leroulx, député de Lorient aux États-Généraux, porte-parole du lobby négociant lorientais ", dans CHAGNY, Robert (dir.), Aux origines provinciales de la Révolution, Grenoble, Presses Universitaires de Grenoble, 1990, p. 309-319. 
négociant - registres de factures, de correspondances, de comptabilité-, en partie exploités par Cécile Haroche ${ }^{5}$ sous ma direction, en 2001 et 2002; elle a réalisé une maîtrise consacrée son activité de négociant à Gand de 1777 à 1785 et un DEA sur son itinéraire de négociant-parlementaire à Lorient. Cet article est une manière de lui rendre hommage. L'ensemble de ces informations a trouvé une petite place dans l'ouvrage dirigé par René Estienne chez Gallimard sur les compagnies des Indes ${ }^{6}$ et dans la Nouvelle Histoire de Lorient ${ }^{7}$ que je publie avec Christophe Cérino aux Presses universitaires de Rennes en 2017. Cet article permet de reconstituer l'itinéraire très particulier de ce négociant qui fut le premier parlementaire lorientais en 1789 et qui finit sa carrière comme sénateur sous le consulat.

\section{Du monde de l'office au négoce}

S'il naît au Blanc, plutôt qu'à Nantes, en 1747, c'est en raison de la fonction de son père, Joseph, sieur De La Ville, qui, avocat au parlement, est devenu sénéchal du Blanc ${ }^{8}$. En effet, ses grands-parents sont nantais et appartiennent au monde de la justice. Son grand-père, Joseph Leroux, conseiller du roi, avocat au présidial, devient maire de Nantes en 1707. Sa grand-mère, Marie Bonnet, est la fille de sieur Louis Malletière, procureur du roi à Nantes. Sa mère, Élisabeth Cellier, est issue d'une famille connue d'Orléans. Avec son frère René, il fait ses études supérieures à Paris et, si l'on en croit sa correspondance, cette orientation vers le négoce n'était pas nécessairement programmée, " avant d'être négociant, j'ai profondément étudié les intérêts des princes ${ }^{9}$ ". Il n'a donc pas pris la même voie que son frère qui fit une carrière brillante qu'il débuta en 1782 comme directeur des Salines du roi en Franche-Comté. Le jeune Joseph passe ses jeunes années à voyager avant de se marier le 24 novembre 1771, à Amsterdam, avec Marie-Thérèse Lefevbure, issue d'une famille huguenote installée à Scheld, près d'Anvers, propriétaire à Nordköpping en Suède d'une manufacture de cuivre et bronze. Si le voyage est indissociable de l'apprentissage du métier de négociant - n'est-il pas polyglotte, maniant le hollandais, l'italien, l'anglais et un peu l'allemand, même si sa langue de commerce est le français - c'est au comptoir chez Jean Texier et $\mathrm{C}^{\text {ie }}$ d'Amsterdam pendant quatre ans et demi, comme commis-négociant, qu'il parfait sa formation,

5. HaRoche, Cécile, Joseph Delaville Leroulx, négociant à Gand, 1777-1785, mémoire de maîtrise, UBS, 2001, et Joseph Delaville-Leroulx, Itinéraire d'un négociant parlementaire, mémoire de DEA, UBS, 2002.

6. Estienne, René (dir.), Les compagnies des Indes, Paris, Gallimard/Ministère de la Défense/DMPA, 2013, p. 76-83.

7. LE BOUËDEC, Gérard, CÉRINO, Christophe, Une histoire portuaire, Une nouvelle histoire de Lorient, Rennes, PUR, 2017.

8. LEMAY, Edna, Dictionnaire des Constituants..., op. cit.

9. Lettre adressée à Messieurs Strekesen et Gavanon, registres de correspondance (1781-1785) du Fonds Delaville-Leroulx versé aux Archives du Service Historique de la Défense à Lorient en 2001, cité par HaROche, Cécile, Joseph Delaville Leroulx..., mémoire de maîtrise, p. 93. 
maîtrisant notamment la comptabilité à partie double, avant de s'installer à son compte à Gand, à 34 ans, en 1778.

\section{La maison de commission Delaville-Leroulx de Gand à Lorient ${ }^{10}$}

Son métier consiste à recevoir en consignation des marchandises, à les stocker dans son entrepôt pour une certaine durée, avant leur simple transfert ou expédition-vente sur des navires, le plus souvent sous pavillon neutre, qu'il doit affréter. Sa rémunération à la commission est de 1 à $2 \%$ ad valorem. Il exerce ce métier de commissionnaire entre 1778 et 1784/85, soit pendant la guerre d'Indépendance américaine où les PaysBas autrichiens bénéficient du statut favorable de neutres pour devenir une plate-forme du commerce international de temps de guerre. Ses registres de comptabilité font apparaître un réseau de 296 partenaires répartis sur neuf pays, où dominent deux espaces préférentiels, d'une part les ports français (42,5 \%) et de l'autre l'ensemble Pays-Bas/Provinces-Unies (43,1\%). Les principaux ports sont, en termes d'importation, Nantes, en tête très largement, Le Havre, Ostende La Rochelle, Gand, Lorient mais aussi Brest, Marseille, Bordeaux, Lisbonne, Cadix, Amsterdam, Hambourg, Elbing, avec une concentration des exportations sur Amsterdam, Bruges, Ostende, Gand, Cadix, Le Havre. Les produits coloniaux occupent une place majeure : les cuirs (de Buenos Aires et Pernambouc), le coton (notamment de Guadeloupe), la cochenille, l'indigo (Saint-Domingue), le tabac (Saint-Vincent et la Virginie), le café (Bourbon et Saint-Domingue), le clou de girofle, la noix de muscade, le poivre (Lisbonne, Amsterdam), le sucre (Jamaïque, La Havane, Martinique, Port-au-Prince au à Saint-Domingue), le thé chinois. Ces produits dominent ses commissions de vente. Il va affréter 37 navires (pour 52 voyages) pendant la période 1780-1785. Il possède en propre un caboteur, le Mercure de Gand, sous pavillon impérial.

Il affrète surtout des navires neutres, usant de faux ou de doubles connaissements pour échapper aux navires anglais. Les navires hollandais dominent, mais après la prise de Saint-Eustache et l'entrée en guerre des Provinces-Unies, il se tourne vers les Danois et les Ostendais.

L'étude de sa correspondance met en valeur l'importance de plusieurs places commerciales qui jouent un rôle majeur dans le fonctionnement de sa maison de commerce. Ses plus gros commettants sont, à Amsterdam,

10. Le Fonds Delaville-Leroulx, acquis par le Service Historique de la Défense, comprend les registres de factures (1777-1785), de comptabilité (1780-1785), de correspondances (1781-1785) qui couvrent la période gantoise de l'activité de Delaville-Leroulx. La période lorientaise n'est couverte qu'à partir de 1793 : le livre magasin (1793-1797), le grand livre des marchandises (1797-1801) dont seules 69 pages sont utilisées, le livre des factures d'achats, comptes et ventes, comptes et frais (1793-1797). Le recours aux rôles d'armement et de désarmement (2P 18, 19, 52, 53) du Service Historique de la Défense de Lorient, les actes notariés des séries $17 \mathrm{C}$ et $6 \mathrm{E}$ et les archives révolutionnaires de la série L 1075 et 1080 des archives départementales du Morbihan ont permis de compléter les sources primaires. 
les maisons Strekeesen, Jean Neel et fils, Jean-Pierre Saint-Martin, Jean Texier et $C^{\text {ie. }}$ La veuve Lambert de Ronquier de Bruges lui fournit des navires à affréter dans le cadre de commissions d'expéditions. Quand il s'agit de voitures pour des transports terrestres, il s'adresse à J.-B. Champon et Flamant frères de Lille. Jean de Vette est son correspondant à Ostende. Il a recours à plusieurs maisons d'assurance, surtout hambourgeoises, où domine la société Pope de Chapeau Rouge. Il dispose à Londres des services du consul impérial, Antonio Bartolomeo Songa, pour récupérer les marchandises au moins, sinon les navires, en cas d'arraisonnement par la course britannique, d'autant qu'il n'est pas impossible que les cargaisons ne se limitent pas aux seules marchandises et matières premières en ces temps de guerre.

\begin{tabular}{|c|c|}
\hline Année & $\mathrm{Nb}$ \\
\hline 1780 & 1 \\
\hline 1781 & 10 \\
\hline 1782 & 9 \\
\hline 1783 & 10 \\
\hline 1784 & 15 \\
\hline 1785 & 6 \\
\hline
\end{tabular}

Comment ce négociant de Gand va-t-il se trouver à Lorient, en 1785, sans doute? Pour y répondre il faut faire le détour par Hambourg où, en 1784, il recherche activement une maison avec magasin à proximité du port, précisant à Charles Lemesle Oursel Isambert et $C^{\text {ie }}$ : « Je saurai parler allemand avant de partir d'ici parce que j'apprends aisément les langues étrangères ${ }^{11}$. „ Pourquoi cette implantation? Il donne une explication dans sa correspondance :

" Le gouvernement désirant établir des maisons françaises dans le nord ayant écrit à ce sujet à toutes les chambres de commerce de France, j'ai été choisi et par les négociants les plus distingués des ports, et par le gouvernement pour former la maison d'Hambourg où je me rendrai [...] avec un demi-million, quatre navires (de 300 tonneaux) et la commission de la Marine, voilà les raisons qui me font quitter ce pays ${ }^{12}$."

Voilà une nouvelle tentative pour reprendre pied sur les routes du grand cabotage du Nord, d'où le pavillon français est largement absent. Il a donc la délicate mission de diriger le comptoir d'Hambourg, l'une des places majeures du commerce européen, pour redonner au pavillon français sa place dans le trafic de la grande rocade européenne. C'est un projet conjoint de la Marine (il fait référence à Castries ${ }^{13}$ ) et d'un groupe d'investisseurs; il

11. Lettre à Messieurs Charles Oursel Isambert et compagnie en 1784, registres de correspondance (1781-1785) du Fonds Delaville-Leroulx versé aux Archives du Service Historique de la Défense à Lorient en 2001, dans Haroche, Cécile, Joseph Delaville Leroulx..., mémoire de maîtrise, p. 96.

12. Ibidem, p. 102.

13. Secrétaire d'État de la Marine. 
cite en particulier les actionnaires principaux, Le Coulteux de La Noray de Paris et Armand François Delaville-Leroulx, de sa parenté nantaise, et des actionnaires minoritaires, Périer (deux actions) de Vizille et Lorient, Walwein (trois actions) de Bruges, les banquiers parisiens Mallet père et fils (une action), Ribard et Levieux (deux actions). L'ensemble de ces actionnaires sont déjà des partenaires commerciaux de Joseph Delaville-Leroux et, derrière les noms de Le Couteulx et de Mallet, c'est la grande banque parisienne que l'on peut identifier et que l'on retrouve dans ses livres de comptes : Girardot Haller et $C^{\text {ie }}$, Deshaumet père, Le Couteulx de La Noray, Lavabre Doerner et $\mathrm{C}^{\mathrm{ie}}$, Mallet père et fils, Thelluson. Son frère René est proche de Le Couteulx et lui-même connaît Necker. C'est donc un projet solide, auquel sont fortement associés le pouvoir et la Marine, doté de moyens importants, un demi-million de livres et quatre navires de 300 tonneaux (payables sur cinq ans). Joseph Delaville-Leroulx précise à Girardot Haller et $\mathrm{C}^{\mathrm{ie}}$ que la mission est primordiale pour l'État français certes, mais que c'est d'abord un projet commercial avec des commissions d'achat de cuivre, bois, laine, toiles, des commissions de vente de sucre, café, indigo, tabac, vins, thé de l'Inde, poivre, fruits..., des commissions d'armement, des commissions d'assurances et des commissions du gouvernement " en tems calme ${ }^{14}$ ".

Or, dans ce projet et dans le réseau de Joseph Delaville-Leroulx, se retrouvent un certain nombre d'acteurs majeurs pro-américains et de la compagnie des Indes, ceux de la banque parisienne - Girardot Haller, Deshommet père, Mallet père et fils, les Anglais Thelusson et Herries -, ce dernier étant l'un des banquiers de la troisième compagnie et du constructeur lorientais, Arnoux Dessaulsays, les deux clans Bérard, celui de Paris (Simon) et Lorient (Jean- Jacques), Augustin Périer le frère de Claude, l'indienneur de Vizille dont la femme est la sœur de Carié, associé de Joseph Delaville-Leroulx dans une société d'armement qu'il crée à Lorient en 1787. Les protagonistes du projet hambourgeois renoncent à se frotter à la concurrence européenne du grand cabotage pour jeter leur dévolu sur la franchise du port de Lorient et le commerce asiatique bien plus profitable. Delaville-Leroulx quitte alors Hambourg et arrive à Lorient. Il a dû s'y établir en 1785. Quand il fait baptiser son fils Louis Joseph le 22 avril 1786 à l'église Saint-Louis, son fils Joseph et sa fille Élisabeth étant parrain et marraine, la famille Delaville-Leroulx habite déjà rue de Luzançay à proximité du port ${ }^{15}$. Le choix de rester à Lorient est confirmé, le 11 novembre 1786, par l'achat, pour 10000 livres, d'une maison dotée d'un grand jardin muré, d'une cour, d'une écurie, d'un pré et d'une lande en banlieue, à Kerlinsachsoie dans la paroisse de Ploemeur ${ }^{16}$.

14. Lettre adressée à Messieurs Girardot Haller et Compagnie en 1784, Registres de correspondance en 1784 du Fonds Delaville-Leroulx versé aux Archives du Service Historique de la Défense à Lorient en 2001, dans Haroche, Cécile, Joseph Delaville Leroulx... mémoire de maîtrise, p. 103.

15. Arch. dép. du Morbihan, série 17 C. Registre des BMS. Arch. mun. de Lorient, série 2MI 100/101; acte notarié de maître Ollivier, le 11 novembre 1786.

16. Kerlinsachsoie est un "village " (= hameau) de la commune de Ploemeur dans la banlieue de Lorient. 
À Lorient, il s'associe avec Hercule Carié, négociant banquier parisien, dans la création d'une société d'armement. Celle-ci dispose d'un unique navire, L'Union, construit à Saint-Malo, dont le tonnage, selon les sources, oscille entre 80 (le plus vraisemblable) et 300 tonneaux. Finalement il reproduit le modèle de sa société gantoise autour du Mercure de Gand. Lors des 18 armements effectués entre juillet 1787 et le 21 novembre 1788, les noms de François Gosselin, Vincent Fardel, Laurent Dréano viennent s'ajouter à ceux des deux associés à la rubrique propriétaires. Les destinations relèvent du cabotage national ou international : Ostende, Dunkerque, Le Havre, Saint-Malo, Brest, Concarneau, Paimboeuf, Nantes, Noirmoutier, Malaga, Valence, Marseille, que l'on peut retrouver chez d'autres armateurs lorientais comme Arnous-Dessaulsays. Il peut s'agir de liaisons directes ou en circuit : Lorient-Noirmoutier-ValenceNantes-Dunkerque-Paimboeuf-Dunkerque-Lorient-Ostende-Lorient. Il devient également un fournisseur habilité de la troisième compagnie ${ }^{17}$ et reprend ses fonctions de commissionnaire-consignataire, comme en atteste la liste des négociants-partenaires importants de la place de Lorient : Arnous-Dessaulsays, l'indienneur suisse Pourtales, l'américain Macarty, Puchelberg, Lanchon, Bouilly, Dussault. Les actes notariés confirment ce positionnement d'intermédiaire de la société " Delaville Leroulx et Carié " dans les opérations de prêt à la grosse pour le financement du commerce de pacotille où ils se portent garants de l'emprunteur auprès du prêteur. Cécile Haroche a ainsi découvert deux cas d'officiers de la compagnie des Indes en 1789. Henry Dauphin de la Branchère, sous-lieutenant sur le Royal Elisabeth qui part pour Pondichéry, contracte deux emprunts à la grosse les 19 mars et 29 avril auprès de Michel Postier et de Fourché de Quéhilla ${ }^{18}$ de Nantes pour une somme totale de 21000 livres pour 18 mois à $25 \%$. Le capitaine du Maréchal de Duran, qui prend aussi la direction de Pondichéry et de la côte de Malabar, Pierre Granière, emprunte 9000 livres auprès des mêmes prêteurs le 20 avril à 26 \% sur 20 mois. Les associés garantissent ainsi en un mois pour 30000 livres d'emprunt à la grosse. Ces informations permettent de comprendre le choix de Delaville-Leroulx de s'installer à Lorient. Le réseau de financiers et de négociants qu'il a tissé comme commissionnaire à Gand pendant la guerre d'Indépendance américaine, à la faveur de la neutralité des Pays-Bas, et qui portait aussi le projet d'implantation à Hambourg, en 1784, d'un comptoir français qu'il devait diriger, s'est engagé à la fois dans la valorisation des relations franco-américaines à partir de Lorient avec la création du port-franc et de la ligne transatlantique Lorient-New York et dans la confiscation du commerce asiatique par une troisième compagnie des Indes. Le Coulteux de La Noray, qui est un peu le pilier de cette constellation, est aussi l'un des pivots des importations des piastres espagnols si essentielles au commerce dans l'océan Indien. Or c'est un proche de René Delaville-Leroulx, son frère, dont on sait les liens avec Necker. En quittant Gand à 38 ans pour Lorient, il s'installe dans un port, portes des Indes et de l'Amé-

17. LA CHIRON CASINIÈRE, Axelle de, Les approvisionnements de la troisième compagnie des Indes (1785-1795), mémoire de maîtrise, Paris 1, 1996.

18. Actuellement Quéhillac. 
rique du Nord, bien intégré dans les réseaux du cabotage d'approvisionnement de matières premières et de redistribution des marchandises des mondes ultra-marins, et dépendant très largement des milieux financiers parisiens qui gravitent autour du pouvoir politique. À son échelle, il fait le choix de s'installer au cœur d'une machine à profit. Le tropisme nord-européen de la troisième compagnie, l'accès à l'T̂le de France au vaste marché de l'océan Indien, les armements illicites à destination de l'Inde, la densité du cabotage atlantique, placent Delaville-Leroulx dans une position qui lui permet comme commissionnaire-consignataire-fournisseur à Lorient d'étendre son réseau commercial. Il fait partie de la deuxième vague d'arrivées de négociants qui viennent s'implanter à Lorient depuis 1770. Ils sont nombreux à s'installer pendant et après la guerre d'Indépendance, leur appartenance franc-maçonne favorise leur intégration. Delaville-Leroulx rejoint la loge de l'Union créée en $1746^{19}$. Son niveau social a poussé certains plus modestes à tenter en vain de créer deux autres loges. Néanmoins en 1789, la loge l'Union est touchée par une scission avec la création de la loge "Heureuse Alliance ".

\section{Le contexte lorientais à l'arrivée à Lorient de Joseph Delaville-Leroulx}

\section{Les espoirs de la frontière américaine au lendemain de la guerre d'Indépendance américaine}

La création du port franc pour favoriser les échanges américano-français était inscrite dans les traités du 6 février $1778^{20}$, et une implantation à Lorient, du fait du rôle de cette ville dans la guerre d'Indépendance, paraît $\operatorname{logique}^{21}$. La question majeure est celle de sa délimitation. La prise en compte des intérêts locaux plaide en faveur d'une assise restreinte de la zone franche sur une partie du port, dans la mesure où celui-ci doit laisser de la place aux armements privés de l'océan Indien et préserver les chantiers de l'arsenal de la Marine, propriétaire du site. Or les Américains vont faire pression pour obtenir l'extension maximale en incluant l'ensemble de la ville. Trois capitaines marchands américains adressent à Benjamin

19. Lors du $250^{\mathrm{e}}$ anniversaire de la loge l'Union, en 1994, la loge lorientaise " Nature et Philanthropie " a publié un opuscule qui donne la chronologie de la création des loges à Lorient : 1744, création de la loge l'Union; 1782, création de loge Saint-Jean de la famille unie du régiment de Condé, scission en 1789 de la loge l'Union avec la création en août de l'Heureuse Alliance. Voir aussi pour l'intégration à Lorient du monde négociant dans les loges : LE BOUËDEC, Gérard, «Franc-maçonnerie et négoce dans le port de la compagnie des Indes ", Cahier de la compagnie des Indes, n 2, 1997, p. 55-61.

20. Un traité d'amitié et d'alliance accorde des privilèges réciproques au commerce de France aux États Unis; un second traité prévoit une alliance, dès que la guerre éclatera entre la France et l'Angleterre. Voir BéLY, Lucien, " la Guerre d'indépendance américaine au cœur des relations internationales ", dans CHALINE, Olivier et al., La France et l'Indépendance américaine, Paris, PUPS, 2008, p. 27.

21. L'ensemble des informations renvoie à l'article suivant : LE BOUËDEC, Gérard, « Lorient pendant la guerre d'Indépendance ", dans CHALINE, Olivier, Les Marines de guerre pendant la guerre d'Indépendance, Paris, Presses universitaires de Paris-Sorbonne, 2013, p. 265-279. 
Franklin une lettre pour se plaindre du manque d'envergure de la zone franche; il intervient auprès des autorités françaises qui prennent en octobre 1784 un nouvel arrêté qui étend au port et à la ville la zone franche. Le 7 juillet, l'ancien consul général américain Thomas Barclay, devenu négociant, se plaint du manque de magasins mis à la disposition de la franchise. Castries, le secrétaire d'État à la Marine, impose au commandant de la Marine à Lorient de libérer des magasins et des caves pour répondre aux besoins du commerce américain. Et il est indéniable que les échanges maritimes entre les États-Unis et Lorient se renforcent. Entre décembre 1785 et décembre 1786 , ce ne sont pas moins de 63 navires américains qui accostent aux pontons du port. 80 \% de ces bâtiments proviennent de six ports principaux (sur 18) : Baltimore, Philadelphie, Boston, Salem, Alexandrie, Newbury. L'inventaire des cargaisons peut laisser croire à une grande diversité. N'y trouve-t-on pas des boucauts de tabac, des barils de blé, de farine, d'huile de poisson, de goudron, de térébenthine, de riz, de raisin et de peaux. Mais en réalité, l'essentiel des cargaisons est constitué de tabac dans une proportion que l'on peut évaluer à environ $80 \%$.

C'est une société d'économie mixte, présidée par le banquier parisien Le Couteulx de La Noray, qui gère la liaison Lorient-New York. La Marine fournit les navires et leurs équipages, les ateliers de l'arsenal assurent la mise en état et la maintenance de la flotte de paquebots. Le groupe bancaire parisien prend en charge les dépenses de fonctionnement contre la perception de taxes sur les objets et les personnes transportés. Le siège est à Paris, Lorient n'est que le port opérationnel, un modèle classique ${ }^{22}$.

\section{Le commerce des Indes et la création d'une troisième compagnie des Indes}

Le commerce des Indes échappait à la zone franche, mais la cohabitation n'allait pas d'elle-même. Celle-ci va devenir plus que complexe quand Calonne prend la décision le 14 avril 1785 de créer une troisième compagnie des Indes avec le monopole des échanges asiatiques au-delà de l'Île de France, ce qui ne met pas fin au commerce privé vers l'océan Indien mais avec comme destination ultime l'île de France ${ }^{23}$. En effet, la guerre finie, le commerce des Indes est à nouveau au cœur d'un affrontement entre les deux groupes financiers et bancaires qui souhaitent mettre la main sur ce commerce colonial derrière une rhétorique dialectique sur les vertus

22. LE BOUËDEC, Gérard, GILLOUARD, Audrey, « Un réseau américain dans les ports français pendant la guerre d'indépendance américaine ", dans Histoire navale, Histoire maritime, Mélanges offert à Patrick Villiers, Université du littoral, 2012, p. 135-140. LE BouËDEC, Gérard, "La constitution des communautés marchandes et la place des étrangers dans la gouvernance des villes marchandes; l'étude de cas de Lorient de 1735 à 1790 ", dans GuERBER, Éric, LE BouËDEC, Gérard, Gens de mer, Ports et cités aux époques ancienne, médiévale et moderne, Rennes, PUR, 2013, p. 161-181.

23. ConAn Jules, La dernière compagnie française des Indes (1785-1875), Paris, Rivière, 1942. 
du monopole et les défauts du commerce libre. Or les deux groupes liés à la grande banque sont représentés à Lorient d'une part par Gourlade et Bernier, qui a des liens avec l'indienneur de Vizille Périer, et par James Bourdieu à Londres qui est proche de l'East India company et qui semblent avoir été les mieux placés, d'autre part par Bérard, associé à l'industrie huguenote de l'indiennage de Neufchatel. Bérard prétend avoir les reins assez solides pour faire fonctionner le monopole à partir de Lorient. C'est Vergennes qui met son veto à une solution sous tutelle de l'East India, imposant un compromis qui impose notamment à Lorient une collaboration entre Jean-Jacques Bérard d'une part, Bernier Gourlade de l'autre.

Voilà les deux dossiers majeurs qui peuvent apporter un avenir brillant au port de Lorient. Or le rêve américain se transforme en cauchemar marqué par un marasme de l'activité économique locale et des faillites de petits commerces. Le 27 février 1785, une assemblée générale des différents corps de la ville est convoquée " pour toutes les plaintes concernant ce qui résulte de la franchise ${ }^{24}$ ». Un véritable cahier de doléances contre la Ferme générale et la franchise est élaboré. L'inspecteur général, Dupont de Nemours, est inondé depuis janvier de mémoires qui émanent des juges consuls, parmi lesquels De Montigny et Godin. Jean-Marie Esnoul-Deschâteles, le maire, s'indigne en écrivant à Calonne le 7 mars 1785 : «Mais qu'est-ce-donc votre franchise ${ }^{25}$ ? " Pour bien montrer qu'il avait entendu les récriminations de son ancien protégé! Il cède aux pressions des groupes financiers en acceptant la création d'une nouvelle compagnie des Indes à monopole le mois suivant, le 14 avril 1785 , ce qui a pour résultat de mettre en difficulté les maisons de commerce qui s'étaient installées à Lorient lors de la libéralisation du commerce de l'Inde. En outre, la franchise se trouve privée des cargaisons de l'Inde. Les registres de faillites du consulat de commerce révèlent à partir de 1786 et surtout 1787 un retournement de conjoncture. Entre 1786 et 1789, 56 faillites, certes d'échelles très différentes, se produisent avec un passif cumulé de 4350500 livres. Les maisons de commerce sont ébranlées en 1787. Courant 1788, notamment au dernier trimestre, en pleine campagne électorale pour les élections aux États de Bretagne, le milieu lorientais est secoué par de grosses faillites, notamment celle de Laurent Esnoul-Deschâteles, le frère du maire. Le marasme économique, qui se lit dans les mouvements du port de Lorient à partir de 1788 : 162 (1788), 129 (1789), 121 (1790), 71 (1791), 40 (1792), et sur le rythme des constructions dans les chantiers privés à partir de 1787, a deux boucs émissaires, la franchise et la compagnie des Indes.

\section{La naissance d'un homme politique (automne 1788-printemps 1789)}

Il est évident que les espoirs de 1785 sont déçus. Au début de l'automne 1788, la bourgeoisie lorientaise est divisée. La municipalité est aux mains de

24. Arch. mun. de Lorient, 7D 19 . Délibération de la communauté de ville de Lorient. 25. Arch. dép. d'Ille et Vilaine, C 733. Lettre de Jean Marie Esnoul-Deschâteles à Calonne. 
la tendance modérée incarnée par le maire Jean-Marie Esnoul-Deschâteles ${ }^{26}$. La préparation de la réunion des états provinciaux, qui interfère avec celle des états généraux, favorise en Bretagne l'émergence d'une tendance radicale. Le maire avait été désigné par la communauté de ville, le 4 octobre, pour être le député de Lorient mais, le 7 novembre, il doit renoncer parce que, anobli depuis 1784, il rencontre une très forte opposition menée par le négociant franc-maçon Godin; le négociant Lemir est nommé à sa place. À Lorient, Delaville-Leroulx appartient au lobby négociant qui fait enregistrer chez un notaire, le 19 novembre 1788, une motion qui répond déjà à la question " qu'est-ce que le Tiers État? " et qui réclame le doublement du tiers et le vote par tête. Le 29 décembre 1788, à Rennes, lors du début officiel de la session, le tiers état refuse de siéger tant que ses revendications ne seront pas satisfaites. Le 17 janvier 1789, la communauté de ville renouvelle la désignation de Lemir, avec mandat de délibérer suivant l'usage, ce qui est une prise de position contre les revendications du Tiers. Le 25 janvier la municipalité se rallie à la thèse du tiers. Il faut dire qu'elle est sous la pression du comité de la commune ouvert aux négociants, artisans et petits commerçants et à la jeunesse patriote qui s'est organisée sous l'appellation "Jeunes gens de Lorient ". C'est cette tendance, alors qu'il s'agit de désigner les députés pour la nouvelle session, qui organise une véritable assemblée " sauvage " de la bourgeoisie radicale qui se tient le 19 janvier à la chapelle de la Congrégation pour fustiger le conservatisme de la noblesse bretonne qui s'oppose au doublement du tiers, et élire les deux députés lorientais pour la réunion des états à Rennes : Delaville-Leroulx et Blain ainé. Pourtant, le 28 janvier, l'échevin Lapotaire est désigné par la communauté de ville comme second député. Cette désignation est annulée en vertu de l'arrêté royal du 30 janvier, qui stipule qu'il doit "être librement choisi par les communautés ". Ces deux députés deviennent les députés additionnels. Le 30 janvier 1789, on assiste à un vrai coup de balai, car la communauté des habitants regroupant 82 représentants des bourgeois, négociants, petits commerçants, artisans et boutiquiers, élit deux nouveaux députés aux états de Bretagne, le négociant Delaville-Leroulx (capité à hauteur de 68 livres pour un revenu annuel de 12000 livres) et le bourgeois Blain l'Aîné (capitation de 9 livres) ${ }^{27}$.

Joseph Delaville-Leroulx est devenu l'un des meneurs du Tiers lorientais. Membre du comité de rédaction du cahier de doléances qui regroupe 12 membres, dont 8 francs-maçons, il est le mieux élu des 18 députés lorientais (dont 12 francs-maçons), le 12 avril 1789, pour aller représenter le tiers de la ville à l'assemblée de sénéchaussée à Hennebont ${ }^{28}$. Il recueille 101 voix sur

26. LE BouËDEC, Gérard, « Une année électorale sans pareille à Lorient (août 1788-avril 1789 ", à paraître à la Société d'archéologie et d'histoire du Pays de Lorient dans la collection " Histoire et Mémoire".

27. LE BouËDEc, Gérard, SOTERAS, Jacques, L'année 1789 dans le pays de Lorient, Comité du bicentenaire de Lorient, 1988, p. 111.

28. Nous avons pu suivre les péripéties de cette période en disposant des échanges de courriers entre les acteurs lorientais (maire, officiers municipaux, communauté de ville, consulat de commerce), le sénéchal d'Hennebont et le pouvoir central (roi, Necker, le 
111, quand ses concurrents n'atteignent au mieux que la barre des 70. Mais l'organisation des élections aux états généraux dans le cadre de la sénéchaussée fait craindre aux bourgeois lorientais que leur députation, noyée dans la masse des ruraux, ne puisse faire entendre leurs revendications et prétendre à l'élection de l'un des leurs pour Versailles. Les députés urbains, au nombre de 26, étaient effectivement en minorité face aux 150 députés ruraux. En fait, dès le 14 octobre 1788, les juges consulaires de Lorient s'étaient adressés à Necker pour que le commerce soit représenté dans la délégation de la sénéchaussée à Versailles, et dès le 5 novembre Necker avait indiqué avoir pris note de cette demande. Aussi, courant mars 1789, Joseph Delaville-Leroulx, du fait de ses relations et de celles de son frère René, est envoyé à Versailles auprès de Necker pour négocier une dérogation au règlement général. Le 29 mars, le garde des Sceaux adresse une lettre au lieutenant général de la sénéchaussée d'Hennebont, Gildas Chrétien de Pommorio, guère enchanté, précisant que le but " était que parmi les députés aux États généraux, qui [devaient] être élus pour le Tiers-État dans l'assemblée générale de votre sénéchaussée, il y en eût au moins un qui fût choisi parmi les négociants et armateurs de Lorient ". Dès lors, la solution était qu'aux deux députés prévus initialement soit ajouté un député spécifiquement élu parmi les négociants et armateurs lorientais dont une liste de 52 membres avait été transmise. Mais la revendication lorientaise allait plus loin car les Lorientais souhaitaient que cette élection soit faite à Lorient et soit donc dissociée de celle des deux députés règlementaires en assemblée générale des délégués des villes et paroisses. Le 4 avril, le garde des Sceaux signifia qu'il fallait qu'elle ait lieu dans le cadre prescrit et que les négociants ne pouvaient pas s'y soustraire. Delaville-Leroulx, déjà membre du comité de rédaction du cahier général de la sénéchaussée, est choisi comme candidat officiel des négociants armateurs. Des critiques vinrent alors de l'ensemble des corps de ville de Lorient contre ce privilège discriminatoire. Mais comment pouvait-il en être autrement? Celui qui avait fait le voyage de Versailles auprès de Necker et obtenu ce siège supplémentaire exclusivement réservé à un négociant ne pouvait être que le candidat du Lorient négociant. Or la surprise vint du score à l'assemblée hennebontaise : sa candidature reçut 124 voix sur 174, soit autant que le procureur d'Hennebont, Le Coroller du Moustoir, et plus que Corentin Le Floch, laboureur de la paroisse de $\mathrm{Lignol}^{29}$. Faut-il là encore s'étonner? Les électeurs choisissent un homme qui évolue dans les cercles du pouvoir. Mais le négoce a su faire passer très largement ses

garde des Sceaux) de la série A Hennebont, numérotés de 1 à 33, des archives départementales du Morbihan et des délibérations de la communauté de ville de Lorient (Arch. mun. de Lorient, 7 D 1-10 : 1787-89). Il faut aussi se replonger dans les publications du bicentenaire : LE BOUËDEC, Gérard, SOTERAS, Jacques, L'année 1789 dans le pays de Lorient, Lorient, Comité historique du bicentenaire, 1988; Le PAN, Hervé, PERron, Yannick, Le Pays de Ploemeur et la Révolution, Comité d'Histoire du Pays de Ploemeur, 1989, p. 39-49; CRÉPEAu, Eugène, Magnanon, Francis, Hennebont et la sénéchaussée en 1789, Imprimerie de Basse-Bretagne, Hennebont, 1988.

29. Le détail des démarches peut être suivi en consultant aux Arch. dép. du Morbihan la série A Hennebont 1, 2, 3, 4, 6, 7, 8, 9, 10, 11, 12, 3, 14, 15, 16, 17, 18, 19, 20, 21, 22, 23, 25, 26, 27, 28, 29, 32, 33. 
revendications dans le cahier de doléances de la sénéchaussée ${ }^{30}$. Il intègre la totalité des revendications des négociants lorientais en matière commerciale. Sur les 180 articles, les articles 100 à 140 sont consacrés au commerce maritime et à la pêche. Les articles 115, 116, 117 concernent les mesures d'interdiction du cabotage aux étrangers, l'exclusivité des exportations de grains aux Français et la fermeture de ports coloniaux aux étrangers. La liberté du commerce avec Madagascar et la fin des entraves imposées par les gouverneurs des îles des Mascareignes fait l'objet de l'article 133. Le maintien des primes pour soutenir la traite tout comme la dérogation à l'importation de produits manufacturés étrangers nécessaires à celle-ci sont dans les articles 122 et 125 . Le commerce de l'océan Indien occupe plusieurs articles : l'abolition des compagnies privilégiées comme la compagnie des Indes et le maintien de Lorient comme port exclusif des retours et des ventes des marchandises des Indes et de Chine (article 118 et 135), le maintien de l'introduction des toiles de coton, des mousselines et des soieries écrues de Nankin acquises sur les marchés étrangers contre paiement d'une taxe d'indult (articles 130-131) et la soumission des cafés Moka à un droit de $15 \%$. L'abolition de la franchise du port de Lorient est affirmée clairement dans l'article 139, comme celle du traité franco-anglais de libre-échange (article 134). Le cahier mentionne aussi la nécessité de construire un phare à Groix et de remettre en fonction la tour à feu de Plouhinec pour sécuriser les accès du port de Lorient, ainsi que la construction d'un pont sur le Scorff pour remplacer le bac afin de faciliter les relations commerciales avec l'arrière-pays (articles 166-167). C'est muni de ce cahier rédigé le 21 avril que Joseph Delaville-Leroulx se prépare à partir pour Paris. Il a alors 42 ans.

\section{Un député exemplaire aux états généraux et à la Constituante ${ }^{31}$}

La députation de la sénéchaussée prend très rapidement le chemin de Versailles. Élus le 22 avril, les trois députés sont versaillais le 29.

30. Thomas-Lacroix, Pierre, "Le cahier de Doléances de la sénéchaussée d'Hennebont ", Mémoires de la société d'histoire et d'archéologie de Bretagne, t. xxxv, Rennes, 1955.

31. Toute cette partie s'appuie sur le dépouillement de la Correspondance de Joseph Delaville-Leroulx (Arch. mun. de Lorient, BB 12-156 (30 avril 1789-9 août 1789) et BB 13-158 (12 août 1789-25 août 1790). Ces deux volumes in folio comprennent au verso les copies des lettres reçues, au recto les copies des réponses apportées par le bureau de correspondance). Joseph Delaville-Leroulx a écrit 195 lettres entre le 30 avril 1789 et le 21 août 1790, à savoir 9 à 18 lettres par mois. Les nouvelles de Versailles-Paris ne se limitent pas aux seules lettres, pourtant abondantes, du député. Celui-ci y joint Le journal des Débats de l'Assemblée, des numéros de certains journaux comme Le Spectateur national. De plus, il a pris soin d'abonner le bureau de correspondance au Journal de Versailles puis au Journal du Point du Jour. Un projet de publication a existé. J'avais fait procéder alors à la transcription des lettres avec du personnel de la Mairie de Lorient et le conservateur du Service Historique de la Défense, René Estienne, avait élaboré un tapuscrit en trois volumes pour une publication prévue par le comité régional du bicentenaire mais qui n'a jamais eu lieu. Ce tapuscrit existe sans doute aux Archives du Service Historique de la Défense à Lorient. 
Joseph Delaville-Leroulx s'installe 40 rue de la Bourdonnaye. C'est alors l'inconnu le plus complet quant à la durée des débats et rien n'est prévu en ce qui concerne l'indemnisation des députés ou du moins le règlement des frais de voyage. Delaville-Leroulx évalue à 720 livres ses dépenses mensuelles, non compris le loyer qui s'élève à 90 livres. La révolution politique qui transforme les états généraux en assemblée constituante oblige le pouvoir à créer une véritable indemnité parlementaire qui permet de couvrir l'aller, le séjour et le futur retour du député. Mais 18 livres par jour, c'est bien juste et le comité lorientais trouve normal de régler les frais que l'indemnité forfaitaire ne permet pas de couvrir. Joseph Delaville-Leroulx est l'un des 63 négociants parlementaires dont une minorité seulement vient des ports : Rouen, Caen, Morlaix, Brest, Nantes, Saintes, Bordeaux, Marseille, Toulon. Il faut noter aussi la présence de trois députés très liés au commerce des Indes : Billette de Vieille Roche (Carhaix), subrécargue sur les navires de la compagnie, les Monneron, Jean-Louis de Pondichéry et Pierre Antoine de l'Île de France.

Cet honneur d'être le député de Lorient devient une fonction envahissante qu'il conçoit comme une mission qu'il ne peut mener à bien sans s'y investir totalement, y compris au détriment de ses propres affaires : " Aucun député n'a une tâche aussi importante que la mienne. Il faut que je réussisse en tout pour reparaître avec avantage au milieu de vous " (lettre du 11 juillet 1789). À la lecture des 195 lettres rédigées par Delaville-Leroulx entre le 30 avril 1789 et le 25 août 1790, ce sont le sérieux et le zèle qui impressionnent. Il se donne tout entier à sa mission au point de mettre en danger sa santé. Son emploi du temps est démentiel. Le 7 novembre 1789, pour excuser le fait qu'il n'a pu effectuer une démarche auprès de ministres, il explique :

" Jamais je n'ai été si captivé de neuf heures et demi jusqu'à trois heures au plus tôt et souvent, jusqu'à quatre ou cinq heures, séances générales. Avant la séance, comité de rapports, trois fois par semaine, comité de Marine à six heures; dans les intervalles, comité de province ou de commerce des députés extraordinaires."

Il assiste donc à toutes les séances plénières, y compris aux séances du soir. En plein débat sur la compagnie des Indes, il reste à son poste alors que le 13 mai 1790 , sa femme meurt en mettant au monde son neuvième enfant. Le 15 mai, il précise : " Je suis abimé de douleur et je ne peux malgré mes sentiments et les intérêts les plus chers quitter un poste que vous m'avez confié et dans lequel je puis seul vous défendre. " Sa femme est inhumée avec tous les honneurs et le baptême de sa fille est grandiose. La municipalité, qui en devient la mère adoptive, la prénomme Louise Joséphine L'Orient, mais elle décède le 30 juin.

Dès le lendemain de son arrivée, Delaville-Leroulx adresse une première lettre à ses commettants. Le 7 mai 1789, un bureau de correspondance, habilité à recevoir le courrier du député et à lui répondre, est mis en place. Toutes ses lettres sont retranscrites sur un registre que la 
population peut consulter tous les jours dans la grande salle basse de l'hôtel de ville de 9 heures à midi. Ce sont ces registres qui permettent aujourd'hui cette étude.

Cette source d'information est fondamentale du fait de ses qualités. Delaville-Leroulx écrit vite, à chaud, sans prendre de recul. Son objectif est d'informer rapidement et avec précision. Certaines lettres sont très proches du reportage journalistique. On ne sent pas du tout une quelconque préoccupation littéraire; le fond, le contenu, l'information priment. Il est présent sur tous les évènements, fait le compte rendu de ses démarches, n'occulte aucun débat, n'hésite pas à faire part des rumeurs et des humeurs. Les envois de ses courriers, tous les deux ou trois jours, se font au rythme des évènements, des tensions, des tendances, des prises de position, des bruits des couloirs ministériels. Les citoyens à Lorient se pressent à l'hôtel de ville pour assister à l'ouverture de sa correspondance. Devant cette faim d'informations, la municipalité prend la décision d'imprimer, chez la Veuve Baudouin, Imprimeur à Lorient, les lettres pour permettre une plus large diffusion des informations versaillaises et parisiennes. Mais deux dangers sont inhérents à cette forme d'information. D'une part, la lecture des lettres peut provoquer des réactions surdimensionnées car elles sont symétriques au ton de la lettre. Or il faut attendre quatre jours pour disposer d'un correctif sur l'ampleur de l'agitation ou de l'inquiétude suscitée. Ainsi c'est la lettre du 13 juillet 1789, et non celles du 14 ou du 15, annonçant l'exil de Necker, les attroupements à Paris, la fermeture des spectacles, la crainte des milieux financiers, qui déclenche, le 17 juillet 1789, la révolution municipale et l'attaque des barrières de la Ferme générale qui cadenassent la ville depuis l'instauration du port franc. Les réactions peuvent donc se faire à contretemps, surtout si, comme pendant l'été 1789 , les évènements se précipitent. Lorient est la ville la mieux renseignée du littoral de la Bretagne sud. Le fait de détenir cette information lui permet de conforter sa position de ville révolutionnaire de référence.

Le député assidu n'est pourtant pas un ténor de l'assemblée; le mandat qui lui a été donné par ses commettants est difficile à conduire. Dès le 30 avril, il participe aux réunions du club breton. Le travail des comités et commissions ne cesse de s'accroître. Il est membre de trois comités : ceux des subsistances (19 juin 1789), des rapports (du 5 octobre au 18 novembre 1789) et de la Marine (6 octobre 1789). Il est aussi submergé de sollicitations de particuliers, et à partir d'octobre toutes les catégories de personnel de la Marine multiplient les correspondances pour être informées sur les réformes à venir. Il publie trois brochures pour faire connaître ses opinions : en septembre 1789, "Opinion sur le système des deux chambres ", système qu'il combat; "Vues générales sur les finances "; et en 1791, "Opinion sur l'établissement à Paris d'une manufacture de tabac ». Il est signataire du serment du jeu de paume, il participe au débat sur la déclaration des droits de l'homme et on lui doit l'expression " contribution publique " dans l'article XIV en lieu et place d'impôt. Le 26 août 1789. Il vote en faveur des 
assignats et pour le rattachement d'Avignon. Mais ce n'est pas suffisant pour être une grande pointure de l'assemblée, et c'est un reproche que la communauté de ville de Lorient lui adresse. Il doit remplir deux mandats, celui de député national et celui de député des négociants lorientais. Le 29 juin, le bureau de correspondance lui adresse une très longue lettre qui définit le mandat impératif, qui est d'œuvrer à la mise en place d'une monarchie constitutionnelle : constitution, réforme des abus, refonte profonde des finances et du système fiscal, roi rendu à son peuple, protection de la propriété en sont les items majeurs. Mais depuis le début de l'automne les intérêts particuliers de Lorient se font plus fréquents dans la correspondance. En fait, depuis la nuit du 4 août, où Delaville-Leroulx est apparu comme un abolitionniste véhément, l'abrogation du privilège de la troisième compagnie est attendue. Les négociants lorientais combattent pour un retour à la situation antérieure à 1785, à savoir que tous les retours et les ventes doivent se faire exclusivement à Lorient. Le député négociant, qui applaudit à la nuit du 4 août, à la déclaration des droits de l'homme et du citoyen, à la reconnaissance pleine et entière de la citoyenneté protestante, qui critique l'instauration du marc d'argent pour être éligible, n'écrit-il pas que "l'amour des noirs ne saurait prévaloir sur celui des concitoyens " : "Le mot de liberté prononcé à ces hommes peut anéantir nos plus belles ressources " (4 janvier 1790). La prospérité économique, déjà compromise, est incompatible avec l'abolition de la traite et de l'esclavage. Dans ces conditions, on ne peut être surpris qu'il ne prenne pas part au vote sur les colonies. Quant à la franchise, on en attend la " destruction " depuis 1785 . L'émeute du 17 juillet 1789 ne s'est-elle pas cristallisée autour des barrières de la Ferme générale? Certes Lorient est le grand pôle économique du sud de la Bretagne en dehors de Nantes, mais cette ville récente est insatisfaite. Elle a obtenu un consulat de commerce et une amirauté en 1782, mais elle revendique d'être le chef-lieu du district, ce qui ne manquerait pas de provoquer des affrontements avec les Hennebontais ${ }^{32}$. À partir d'octobre 1789 , ce sont ces dossiers particuliers qui envahissent les courriers entre le député et le bureau de correspondance. $49 \%$ des lettres du bureau et 58,5\% de celles du député contiennent des paragraphes consacrés aux intérêts particuliers de l'élite lorientaise. C'est le 21 septembre que Delaville-Leroulx reçoit ce second mandat impératif en ces termes :

" Nous ne doutons point que vous n'employez tous les moyens qui sont en vous pour que nos espérances sur les objets qui intéressent plus particulièrement notre ville se réalisent. Nous voulons dire : la liberté du commerce de l'Inde; l'adhésion des chambres de commerce pour le retour des bâtiments en ce port et enfin la destruction de cette funeste franchise. "

32. Les 23 et 28 décembre le bureau de correspondance de Lorient écrit une diatribe contre Hennebont et les courriers du 26, 31 mai et 7 juin, lors du débat sur la fixation du chef-lieu du district montrent que Lorient a l'impression d'être victime d'une machination où le monde rural s'est coalisé derrière Hennebont contre Lorient. Le 12 février précédent, il a aussi reproché à Delaville-Leroulx de n'avoir pas su manœuvrer lors du débat sur la fixation du chef-lieu du district. 
La double mission du député, "veiller au bonheur de la patrie et aux intérêts de la ville " se révèle difficile à mener. La municipalité est volontiers critique sur son manque d'envergure. Ainsi, le 11 septembre, elle lui reproche de n'avoir pas réussi à se faire élire au comité du commerce : "Nous voyons avec peine que vous ne fassiez pas partie du comité du commerce [...]. Le commerce de l'Inde, si important pour la nation, si intéressant pour la Bretagne et pour ses villes en particulier, pourra entraîner des discussions qu'il eût été nécessaire de charger quelqu'un plus particulièrement instruit à débattre", sous-entendu un Lorientais plutôt qu'un Malouin ou un Nantais. Le 12 février 1790, lors du débat sur la fixation du chef-lieu de district, il reçoit cette remontrance : "Nous sommes fondés à croire que vous avez laissé échapper le plus puissant moyen de faire valoir nos droits. " Parfois le député a du mal à concilier son idéal humaniste et la défense des intérêts particuliers de son milieu, comme lors du débat sur la traite le 15 février 1790 :

" J'ai conclu publiquement, parce que je crois un axiome, c'est que si le philosophe doit s'occuper du bonheur de l'univers, le législateur ne doit s'occuper que des lois qui doivent faire le bonheur de son pays. Je n'ai pas craint de dire qu'en ce sens, je croyais que la liberté, la prospérité de la France étaient attachées à la servitude des lois. En pareil cas, on ne peut pas consulter son cœur, il faut écouter sa raison, et le sentiment le plus humain qui rendrait mon pays malheureux est, par l'état que j'occupe, un sentiment que je vais étouffer. "

Face aux remarques des membres du bureau de correspondance devant ses états d'âme, il doit, le 14 novembre 1789, les rassurer sur sa mission " faire que les affaires de Lorient soient prospères " et donc faire aboutir ses revendications. Lorient, prototype de la ville patriotique et révolutionnaire, que Delaville-Leroulx incarne parfaitement, en avance sur les décrets de l'assemblée, le montre en versant au trésor un don patriotique très important de 303000 livres le 3 octobre 1789. Mais la remarque de Delaville-Leroulx, le 3 octobre, est de joindre à l'envoi du don patriotique un courrier expliquant l'articulation entre ses deux mandats. Dans celui-ci, il conseille aux membres du bureau de correspondance d'inclure une adresse dans laquelle ils préciseraient que

"les dons patriotiques se seraient élevés à des sommes bien plus considérables si Lorient eût joui du commerce libre de l'Inde, au lieu d'être alimenté par le petit nombre de vaisseaux que la compagnie emploie au commerce; si enfin la franchise du port n'eut mis d'autres entraves à l'industrie d'habitants, ce qui a produit le renversement d'une infinité de fortunes ".

Le Lorient négociant, si arrogant au point de ne pas voir que Lorient n'appartient pas à la catégorie des très grands ports, fait cette remarque cinglante le 10 février 1790 : "Vos concitoyens, Monsieur, sont étonnés et attristés de ne voir, jamais, dans les procès-verbaux de vos séances, aucune mention de notre ville. " Lorient se veut un modèle, mais veut que cela se sache. Cette auto-perception, pleine d'hybris, de leur ville par les Lorientais explique leurs déceptions quand elle n'obtient pas ce qui lui est " dû ». 
Alors quelle stratégie pour réussir? D'abord dissimuler l'intérêt particulier dans une littérature d'intérêt général. Delaville-Leroulx plaide à l'assemblée le retour, les désarmements et les ventes des produits de l'océan Indien au port de Lorient, le 20 mars 1790, car « l'intérêt général demandera toujours cette concentration si les ventes des produits de l'océan Indien se font à des époques annuelles ". Cet argument ressurgit par le biais d'une pétition de 24 négociants acheteurs non lorientais en faveur du maintien des désarmements et des ventes à Lorient, qu'un député extraordinaire, Blain cadet, vient porter jusque sur le bureau de l'assemblée, en franchissant la distance Lorient-Paris en 47 heures afin que Delaville-Leroulx puisse mieux défendre l'intérêt particulier de Lorient. Devant l'incapacité physique des députés à assumer toutes leurs obligations, des comités constitués de députés extraordinaires sont mis en place. C'est une occasion que Lorient ne laisse pas passer. Ainsi le comité de commerce et des manufactures, créé à côté du comité de commerce et d'agriculture, et qui regroupe des députés supplémentaires des villes industrielles et portuaires, offre la possibilité à Lorient, dans la mesure où Delaville-Leroulx n'a pu se faire élire au comité du commerce des villes, d'envoyer une députation de deux membres, les négociants Bondeville et Puchelberg. Bientôt au nombre de quatre, ils constituent en réalité des lobbyistes au sens moderne du terme. Ils préparent des dossiers. Ainsi en janvier 1790, circule un ouvrage sur le commerce des Indes dont l'auteur est le député extraordinaire de Lorient, Guillois. Ces députés supplémentaires se rendent auprès de tous les comités, viennent assister aux séances du comité breton devenu la Société de la Révolution en janvier 1790. Le 24 février, Delaville-Leroulx révèle que la position du comité de Bretagne sur la question des désarmements a été rédigée par les deux députés extraordinaires, Puchelberg et Guillois. En juin 1790, Bondeville est affecté auprès de la délégation de Marseille pour neutraliser l'un des députés extraordinaires du port méditerranéen. Sur le dossier du chef-lieu du district, les députés extraordinaires ont pour mission de contrecarrer l'influence des deux députés ordinaires de la sénéchaussée qui défendent la candidature d'Hennebont, ancienne capitale de la juridiction, contre celle de Lorient.

Delaville-Leroulx est parti à Versailles dans un enthousiasme généreux. À l'automne, confronté aux difficultés de la refonte des institutions, il est devenu plus réaliste et il essaie de concilier ses deux mandats. Les difficultés rencontrées et les lenteurs irritent les membres du bureau de correspondance de Lorient qui mesurent mal ce qu'est le paysage politique versaillais et parisien. Le 4 août 1790, il dresse un tableau très clair de la pratique quotidienne du député qu'il est après plus d'un an d'exercice :

"Mon zèle est certain, ma conduite est pure. Vos ordres sont pour moi des lois que je ne transgresserai jamais. Dans tous les temps, j'irai vous rendre compte de tout ce que j'aurai fait en vos mains pour que vous me jugiez. Mais je vous prie de bien peser l'avantage de notre cité. Et comme je puis obtenir péniblement l'un ou l'autre des établissements dont il s'agit [la capitale du district ou le tribunal], je désire qu'après avoir reçu votre vœu, vous soyez satisfaits de ce que j'aurai pu obtenir. Je ferai donc pour 
le mieux de vos intérêts. Si je ne réussis pas, j'en serai plus affligé qu'aucun de mes concitoyens."

Il obtient l'abolition de la franchise le 27 mars 1790, la liberté du commerce de l'Inde le 5 avril 1790, mais le 19 juillet 1790, la déception est grande de devoir partager les retours avec Toulon. Par décret des 3 avril-2 mai 1790, soit quelques mois avant la clôture de la liquidation de la seconde compagnie le 14 août, la liberté du commerce au-delà du Cap de Bonne Espérance est rétablie et le privilège de la compagnie est aboli mais rien n'est totalement réglé. Il faut attendre une décision du 19 juillet 1790 , reprise par un décret du 20 juin-6 juillet 1791 pour connaître la nouvelle configuration des échanges. Si la liberté du lieu d'armement est rétablie pour tous les ports ouverts aux colonies françaises d'Amérique, celle du retour n'existe pas, Lorient reste théoriquement le port de retour mais doit partager cette fonction avec Toulon; encore faudrait-il que ce soit applicable. En fait, si elle perd son monopole, la compagnie, en tant que compagnie privée, poursuit ses activités à Lorient comme l'avaient décidé dès mai 1790 ses administrateurs, et c'est une chance pour Lorient. Elle commerce avec la Chine, le Bengale, Pondichéry et la côte de Malabar. Mais en ce qui concerne les institutions, Lorient doit se contenter du tribunal, Hennebont capitale de la sénéchaussée gardant le district.

\section{Le commissionnaire consignataire accède au Sénat (1791-1803)}

Après avoir exercé son mandat de député à la Constituante, celui qui est inscrit aux Feuillants aux "Amis de la liste civile ", non éligible à la Législative, n'assume pas de responsabilité à Lorient. Il demeure néanmoins une grande figure politique locale au moins jusqu'à l'automne $1793^{33}$. C'est une autorité morale, au comportement exemplaire : n'a-t-il pas hésité à sacrifier sa vie familiale au service de la nation et de sa ville? Cette lettre de la municipalité du 23 mars 1792 est éloquente :

\footnotetext{
"Nous avons vu Monsieur, avec attendrissement et reconnaissance la nouvelle preuve de votre attachement aux intérêts de notre cité. Nous ignorons quel sort nous est réservé et quel qu'il puisse être, nous nous y soumettons, mais nous ne sommes pas surpris de voir que l'intérêt particulier détourne les regards du corps législatif des grands et importants objets qui devraient tant l'occuper dans la position critique où se trouve la patrie. "
}

Il continue d'incarner la primauté de l'intérêt général national mâtiné d'intérêt lorientais. De quoi s'agit-il? L'embargo sur les exportations de matières premières coloniales à partir du $1^{\mathrm{er}}$ mars 1792 complique les échanges. Ainsi en février et mars 1792, des navires anglais entrés dans le port, chargés de cargaisons de balles de coton destinées à l'exportation, se voient imposer le déchargement et la mise en magasin, ce qui déclenche

33. On peut le suivre au détour de certaines délibérations de la municipalité de Lorient (Arch. mun. de Lorient, série 7 D1 : 2/8/1791-19/2/1793 [7D1/22] et 20/2/1793-22/10/1794 [7 D1 24]). 
des protestations des négociants anglais et même l'intervention de l'ambassadeur auprès du roi. Finalement les navires sont autorisés à partir sous le prétexte que les décrets d'application ne sont pas publiés. Joseph Delaville-Leroulx, ancien député de Lorient à la Constituante, dénonce en fait une manipulation des négociants avec l'aide de l'ambassadeur anglais pour contourner l'embargo, car les cotons sont destinés à un trafic illicite en direction d'Ostende. En avril, on observe le même processus avec la Princesse de Piedmont arrivant de Pondichéry avec 1850 balles de coton à la consignation de Senn et Biderman. Dans le port, un caboteur hollandais, Le jeune Jan d'Amsterdam attend pour charger la cargaison au nom de Bérard et Guérard avant de prendre la mer pour Ostende et c'est le même argument qui permet d'échapper à l'embargo. Le 18 mars 1794, DelavilleLeroulx écrit au district d'Hennebont pour réclamer des semences afin d'emblaver des terres qu'il vient de faire défricher; il indique que la production est destinée à la République. Il est vrai que depuis janvier la pénurie alimentaire impose aux Lorientais des cartes de rationnement.

Depuis le mois de mai 1792, sa nombreuse famille est installée à Paris, mais il fait des voyages réguliers à Lorient. D'ailleurs ce courrier de la municipalité du 6 mai 1792 l'exprime parfaitement :

" La nouvelle de l'arrivée de votre famille à Paris et en bonne santé nous a été infiniment agréable; nous partageons la satisfaction que cette réunion vous a causée. D'un autre côté nous avons vu avec peine, ces jours derniers que la déclaration de guerre vous a forcé à faire venir à grands frais vos effets par la voie des rouliers. Si nous pouvons être de quelque utilité dans les relations que vous pourrez conserver avec notre ville, nous vous prions de compter sur nous."

L'élimination des Girondins en juin 1793 entraîne dans le district et à Lorient une réaction immédiate sous la forme d'une force interdépartementale destinée à sauver la République. Ce choix " erroné " n'empêche pas la municipalité d'adhérer sans réserve dès juillet 1793 à la constitution montagnarde. Le 27 juillet 1793, Delaville-Leroulx se présente au bureau municipal de Lorient pour que son adhésion personnelle à la nouvelle constitution figure à côté de celle de la municipalité, ce qui est accepté. Mais cette orientation girondine des Lorientais entraîne des sanctions. Le 31 août, le maire Jean-Jacques Trentinian et trois personnalités sont arrêtés et transférés à Paris. Le 21 octobre 1793, l'ensemble du conseil général est suspendu.

L'imbrication des affaires de la compagnie et des conflits politiques sous la Montagne est évidente à Lorient. La liquidation de la compagnie, inéluctable après le décret de suppression le 24 août 1793 des sociétés par actions, se fait dans un contexte de scandale politico-financier. Pour échapper à un impôt sur les dividendes, voté par l'assemblée législative en août 1792, les actionnaires et administrateurs de la compagnie avaient imaginé un système pour camoufler leur fraude fiscale. Afin de la dissimuler définitivement, ils proposèrent d'organiser eux-mêmes la liquidation de la compagnie. Le 27 août 1793, plusieurs députés sont chargés de la liquida- 
tion, dont Fabre d'Églantine. Or, lors de la rédaction du décret de liquidation, en octobre 1793, Fabre d'Églantine, signataire du texte, se retrouve au centre d'une manipulation révélant " une conspiration pour écarter le gouvernement ". En octobre, les marchandises et navires de la compagnie estimées à 28544000 livres sont réquisitionnées et, le 6 décembre 1793, les marchandises entreposées à Lorient sont mises à la disposition du comité de Salut public; les directeurs sont emprisonnés le 18 mars $1794^{34}$. La question du décret est alors un des moteurs de la crise politique qui permet à Robespierre d'éliminer pendant l'hiver 1793-1794 les oppositions de gauche et de droite. Lorient, déjà suspecté en juillet 1793 d'avoir soutenu les Girondins - ce qui avait entrainé l'arrestation du Maire Trentinian, son transfert à Paris le 31 août et l'arrivée au pouvoir d'une municipalité montagnarde -, se retrouve au cœur du scandale de la compagnie des Indes qui est détentrice, en plein effondrement de l'assignat, d'un trésor que sont les marchandises de l'océan Indien stockées dans ses magasins mais aussi dans ceux des particuliers au port ou dans la ville de Lorient. En janvier 1794, ce sont les négociants privés, parmi lesquels les Bérard, Rivier, Senn et Bidermann, qui doivent déclarer leurs crédits et leurs débits " en pays neutres " et " en pays ennemis ". Entre mars et mai, en vertu du décret du 13 mars 1794, sont enregistrées 169 déclarations de marchandises détenues dans leurs magasins par des négociants et des particuliers, soit : 583 balles de coton en laine, 133862 pièces de cotonnades, près de 9900 balles de café de Bourbon et 731 de café moka, 492 caisses, 17 caissons et 410 boîtes de thé, 5017 futailles, barriques, barils et caisses et sacs d'épices, 71 caisses de cannelle. Les marchandises des Indes sentent la poudre. Des scellés sont placés sur les biens de Delaville-Leroulx, Monneron et Besné sont mis en état d'arrestation et la commune montagnarde de Lorient sollicite par des courriers des 20 et 25 juin 1794 du comité de Salut public, l'autorisation de les incarcérer. Ce qui semble avoir eu lieu, car Delaville-Leroulx donne à son gendre J.-B. Morel une procuration pour gouverner et administrer pendant son absence. Ce n'est que le 2 juillet que la commune de Lorient reçoit les injonctions du comité de Salut public. La date est trop proche du 9 thermidor et de l'arrestation de Robespierre pour être suivie d'effets.

En cette année 1794, l'application du Maximum pose en outre de gros problèmes. Ainsi quand la barque l'Angélique de Bordeaux débarque 21 barriques de vin de Médoc de qualité supérieure valant à la revente 260 livres l'unité, leurs destinataires se voient imposer le tarif maximum de 100 livres. Globalement les négociants se disent choqués par les méthodes d'évaluation. Ainsi, quand les chasse-marée le Saint-Pierre et le Marie Thérèse accostent en provenance de l'île de Ré avec respectivement des cargaisons de vin

34. Estienne, René (dir.), Les compagnies des Indes, Paris, Gallimard/Ministère de la Défense-DMPA, 2013, p. 76-83 (voir le chapitre écrit conjointement par Thierry Claeys et Gérard Le Bouëdec); MATHIEZ, Albert, Un procès de corruption sous la terreur, l'affaire de la compagnie des Indes, Paris, librairie Félix Lacan, 1920; MichEL, Eudes, " Une interprétation mathiezienne de l'affaire de la compagnie des Indes ", Annales historiques de la Révolution françaises, $\mathrm{n}^{\circ} 244$, avril-juin 1981, p. 239-261. 
rouge et de vin blanc-eau de vie, les experts nommés par la municipalité, qui montent à bord, déterminent leur prix après les avoir simplement goûtés. En avril 1794, les circuits financiers du commerce sont devenus difficiles. Ainsi, Bérard qui a expédié des thés à Ostende à son correspondant Beuquet et compagnie attend en vain des nouvelles du paiement chez Parish et $\mathrm{C}^{\mathrm{ie}}$ d'Hambourg et ses contacts à Amsterdam (Hope et $\mathrm{C}^{\mathrm{ie}}$, Hayaere et Cie) et à Londres (Herries et $\mathrm{C}^{\mathrm{ie}}$ ) ne lui sont d'aucun secours. Du côté des négociantsarmateurs eux-mêmes, plusieurs indices montrent néanmoins une volonté de continuer sur la lancée des armements de la période 1785-1789.

La situation du citoyen commissionnaire et de sa famille est complexe. Son mandat de député a eu un effet négatif sur ses affaires. Il obtient d'ailleurs le 6 mai 1792 que sa contribution patriotique soit réduite à 300 livres. Dès le 16 février 1791, la municipalité avait sollicité du contrôleur général des finances Delessert la direction du bureau des timbres pour la fille aînée de Delaville-Leroulx en expliquant " qu'il a payé sa dette à la patrie pour le sacrifice de presque toute sa fortune ". Néanmoins il est à peu près certain que ses affaires continuent sous la raison sociale " Delaville-Leroux et Carié ". Il fait d'ailleurs des allers-retours rapides à Lorient qui doivent lui servir, au moins avant 1792, à suivre sa maison de commerce. À partir de 1793 , il exerce sous la seule raison sociale " Delaville-Leroux et $\mathrm{C}^{\mathrm{ie}}$ " et la consultation des livres de magasin (mars 1793-mars 1798), de marchandises (1797-1801), de factures (1793-1797) et des actes notariés montre qu'il a repris ses activités à temps complet. Qu'apprend-on? Son positionnement d'intermédiaire se lit dans les sommations à payer, la substitution dans les pouvoirs, les récépissés, les comptes courants, les notes de frais et surtout dans les nombreuses procurations. Son activité de commissionnaire import-export se lit dans la large gamme des 136 produits surtout ultramarins qu'il traite, parmi lesquels, les thés, les cafés (9 qualités différentes), les sucres (6 qualités), un large éventail d'épices, 13 sortes de tabac, un panel immense de textiles de coton ( 7 qualités), de mouchoirs de toute qualité, de guinées, de mousselines, de soieries indiennes et italiennes. Ses 362 clients sont certes des Lorientais, mais viennent aussi des autres ports où il dispose de vraies succursales tenues à Brest par Guithern père et fils, à Rouen par la Vve Léon Duvergier Le Boucher et $\mathrm{C}^{\mathrm{ie}}$, à Nantes par Delaville et fils. Quand on parcourt son "État de marchandises que les citoyens Joseph Delaville-Leroulx et $\mathrm{C}^{\mathrm{ie}}$ de Lorient ont en leur possession au lieudit Orient tant pour leur compte que pour compte d'amis et des marchandises qu'ils ont pour leur compte dans l'intérieur de la République " daté du 9 floréal an 2 et établi conformément au décret du 13 mars 1794, on est surpris et impressionné par le volume et donc la valeur des marchandises et on comprend mieux que Joseph Delaville-Leroulx ait pu être une cible du comité de Sûreté générale, tant le trésor des Indes sentait la poudre en $1794^{35}$.

35. Arch. dép. du Morbihan, série L 1080. Je suis redevable aux membres du comité du bicentenaire de Lorient qui ont dépouillé aux archives départementales les liasses L 1075 à 1080 . 
Delaville-Leroulx comme propriétaire ou consignataire détient d'abord des marchandises dans les magasins du port de Lorient :

\begin{tabular}{|l|l|}
\hline Delaville-Leroulx et Cie & $\begin{array}{l}199 \text { boites de thé Soatchan; } 1 \text { baril Sagon, } \\
9 \text { sacs de poivre; } 56 \text { balles (407 pièces) de } \\
\text { guinées bleues }\end{array}$ \\
\hline $\begin{array}{l}\text { Augustin Monneron (Paris), } \\
\text { Armand-François Delaville et Dela- } \\
\text { ville-Leroulx et Cie }\end{array}$ & 357 sacs de cauris \\
\hline Javier Monneron (île de France) & 10 caisses et 1 baril d'indigo \\
\hline Le Foulon et Charbonnier (Nantes) & 575 balles de café Bourbon \\
\hline Le Biré et Verdonnet (Bordeaux) & $\begin{array}{l}54 \text { balles de café Bourbon et } 6 \text { balles de coton } \\
\text { d'Île de France }\end{array}$ \\
\hline Bouissant & 65 balles de café Bourbon \\
\hline A. Barbier (Paris) & $\begin{array}{l}12 \text { balles et } 2 \text { ballotins de café Bourbon; } 1 \text { bal- } \\
\text { lotin d'indigo }\end{array}$ \\
\hline Laffond (Paris) & 2 balles de café Bourbon et 1 baril d'indigo \\
\hline Dumolard (Paris) & 5 balles de coton d'Île de France \\
\hline Citoyenne Girbonde (Quimper) & 35 pièces de guinée bleue \\
\hline Mottair Narbonne (île de France) & 5 balles de café Bourbon \\
\hline & $\begin{array}{l}2 \text { balles Caskety; } 1 \text { petite caisse de coton } \\
\text { cambre; } 7 \text { barriques Cachon, } 1 \text { caisse, } 6 \text { bar- } \\
\text { riques et } 1 \text { tierçon d'extrait de casse; } 1 \text { caisse } \\
\text { d'anis étoilé; } 100 \text { balles de café Bourbon; } \\
12 \text { caisses d'indigo; } 48 \text { macoutes, } 32 \text { sacs et } \\
14 \text { barils de poivre }\end{array}$ \\
\hline Louis Monneron & \\
\hline
\end{tabular}

Mais il dispose aussi dans ses magasins privés dans la ville de Lorient des marchandises en propre ou en consignation :

\begin{tabular}{|l|l|}
\hline Delaville-Leroulx et $C^{i e}$ & Thé : 10 boîtes de thé divers; 1 quart de \\
& thé Hayssen, 8 caissettes de thé Choulang; \\
& 2 ballotins de café Moka; 25 pièces de mous- \\
& seline; 52 pièces de mouchoirs, 19 plateaux \\
& de Chine; 13 ballots avec 414 pièces de toiles \\
& blanches provenant de prises anglaises ou \\
& de Laval; 1 barrique de soude; 1 barrique \\
& de craye de Briançon; 3 caisses de glace, \\
& 20 canevettes. \\
\hline Louis Monneron & 12 caisses de Baume; 1 harpe et 1 piano \\
\hline
\end{tabular}


Dans ses trois filiales, à Nantes, Rouen et Brest, il dispose aussi de marchandises dans les mêmes conditions :

\begin{tabular}{|l|l|}
\hline $\begin{array}{l}\text { À Nantes, chez Delaville et fils, pour le } \\
\text { compte de Delaville-Leroulx et Cie }\end{array}$ & $\begin{array}{l}57922 \text { livres-poids de sucre brut et } \\
19909 \text { lp de sucre blanc; } 11766 \text { lp de } \\
\text { café; } 15 \text { balles de toiles de Bretagne; et } \\
15 \text { balles de toiles halées }\end{array}$ \\
\hline $\begin{array}{l}\text { À Rouen, Chez La Vve Léon Duvergier, } \\
\text { Le Boucher et Cie, pour le compte de } \\
\text { Pierre Lebeau de Lorient }\end{array}$ & $\begin{array}{l}10 \text { futailles, 26 barriques et } 1 \text { tierçon } \\
\text { d'indigo (à } 25 \% \text { d'intérêt) et } 5 \text { balles } \\
\text { de coton du Bengale (à } 50 \% \text { d'intérêt) } \\
\text { (sans doute dans le cadre d'un finance- } \\
\text { ment à la grosse) }\end{array}$ \\
\hline $\begin{array}{l}\text { À Brest, chez Guithern père et frères } \\
\text { pour le compte de Delaville-Leroux et } \\
\text { Cie et de Pierre Le Beau }\end{array}$ & $\begin{array}{l}50 \text { caisses de sucre brut à 25 \% d'intérêt } \\
\text { (sans doute aussi dans le cadre de finan- } \\
\text { cement à la grosse) }\end{array}$ \\
\hline
\end{tabular}

Il détient en outre personnellement 378 pièces de toile d'Irlande issues de prises anglaises et acquises par achat auprès de trois négociants lorientais, Drogart, Bijotat et Desforges. Cela pose une question difficile à résoudre du fait de l'insuffisance de l'information livrée par des sources manquantes de la période 1790-1793. S'il est clair que ses affaires sont affectés par son absence lors de son mandat de député, il est difficile de croire qu'elles n'aient pu reprendre vigueur qu'en 1793, même si cette année-là, sa société Delaville-Leroulx et $C^{\text {ie }}$ prend le relais de la société avec Carié. La présence de son gendre auquel il donne une procuration pendant son arrestation est aussi un indice de la continuité des affaires. Néanmoins, l'inventaire du stock et le réseau portuaire ne doivent pas être surévalués à l'aune de la situation de 1794 et peuvent aussi traduire les difficultés des échanges durant cette période de guerre et de blocus.

Après la municipalité de transition de l'après-thermidor, où on observe encore un certain équilibre entre les négociants (21) et les membres du petit commerce et de l'artisanat (14), celle qui est élue les 19 et 20 novembre 1795 voit le retour de ceux qui avaient été écartés sous la Montagne. Trentinian, qui fut maire jusqu'au 31 août 1793, retrouve son fauteuil, et des hommes de 1789 refont surface. 35 \% des électeurs des assemblées primaires sont issus du lobby négociant de 1789 et $50 \%$ des élus faisaient partie de la première municipalité de la Révolution. C'est le retour au niveau local de Joseph Delaville-Leroulx ${ }^{36}$ qui se fait élire officier municipal. Il entre en outre au tribunal de commerce mais il demande immédiatement une

36. Son frère René, eut aussi une carrière brillante. L'ancien directeur des Salines du roi, fut administrateur de la commune de Paris pour la section du Temple en 1789, ministre des contributions publiques en juillet-août 1792 (en fait il assure l'intérim de Clavières), directeur des bâtiments et des constructions sous le Directoire puis du commerce français puis consul à Rotterdam. 
dérogation pour absence de trois mois afin de régler des affaires urgentes : affaires commerciale et financières ou raisons familiales?

En fait sa vie familiale et politique va l'éloigner définitivement de Lorient. Depuis 1792, sa famille est à Paris et il fait des allers-retours très fréquents à Lorient. Il se remarie, le 25 juin 1796, à Chenonceaux avec Madeleine Suzanne Dupin, veuve de Pierre Armand Vallet de Villeneuve. Deux de ses filles, Marie-Élisabeth et Marie-Guillemine, ont acquis une certaine réputation dans le Paris de l'art comme peintres. Le néo-parisien va bientôt entamer une nouvelle carrière politique. Il fait partie des 38 anciens élus de la Constituante, de la Législative, de la Convention, du conseil des Anciens et des Cinq Cents qui vont être cooptés par Bonaparte pour faire partie du Sénat. Ce négociant-député à la Constituante, favorable au coup d'état de Brumaire, fort d'une réputation de respectabilité, de modération, a peut-être été proposé par Claude Perrier du cercle des banquiers-négociants consulté par le Premier consul ${ }^{37}$. Ce dernier (manufacturier indienneur à Vizille et banquier ${ }^{38}$ ), est le frère d'Augustin Perrier, beau-frère de son ex-associé Carié et que Delaville-Leroulx a côtoyé à Lorient comme négociant et administrateur de la $3^{\mathrm{e}}$ compagnie des Indes. Il est nommé, le 25 décembre 1799, sénateur. Il garde son siège jusqu'au 3 avril 1803. Alors qu'il allait dîner chez le Premier consul, il meurt à 56 ans d'une crise cardiaque $^{39}$.

Cet article présente la trajectoire particulière d'un commerçant consignataire au cour d'une économie maritime spéculative, à Gand durant la guerre d'indépendance, puis au port de Lorient de 1785 à 1795, véritable point nodal opérationnel d'une stratégie économique, financière et politique dont il n'est qu'un instrument. Les revers du modèle lorientais en pleine période prérévolutionnaire, qui révèle la fragilité de la place et son caractère artificiel, créent les conditions pour que Joseph Delaville-Leroulx s'engage dans une carrière politique en devenant le député des négociants lorientais à l'assemblée constituante. Très fidèle à ses engagements auprès de ses commettants, il doit naviguer entre les contradictions des mandats qui lui sont imposés et dans une conjoncture économique et coloniale mise à mal par le blocus puis par la guerre qui menacent le modèle lorientais, idéal qu'il est censé sauvegarder. Delaville-Leroulx sort grandi de ce premier mandat politique et acquiert une solide réputation. Il semble reprendre ses activités de commissionnaire-consignataire comme le montre l'état de ses magasins à l'été 1794, ce qui le désigne à la vindicte du pouvoir

37. ClaEYS Thierry, Dictionnaire biographique des financiers en France au XVIII siècle, Paris, SPM, 2009, p. 209.

38. Une dynastie bourgeoise dans la Révolution, Les Périer, catalogue de l'exposition organisée sous le patronage du Conseil général de l'Isère, au musée de la Révolution française au château de Vizille du 14 juillet au 16 décembre 1984.

39. Cf. BRotonne, Léonce de, Les sénateurs du Consulat et de l'Empire, Paris, Éditions Charavay, 1885, (réimp en 1974), p. 14. 
montagnard. Cet humaniste, qui exprime parfois ses états d'âme, quand il s'agit de l'esclavage et de la traite, ce modéré, très proche des cercles des pouvoirs économiques, financiers et politiques parisiens, quand prend fin la Terreur, en soutenant le coup d'État de Brumaire, s'offre une seconde carrière politique en devenant sénateur en 1799.

\section{RÉSUMÉ}

Cet article présente la trajectoire de réussite d'un négociant-commissionnaire-consignataire intégré dans les réseaux commerciaux, financiers et politiques. Installé à Gand pendant la guerre d'indépendance américaine, après un apprentissage à Amsterdam, il migre en 1785 vers Lorient, porte des Indes et des États-Unis. La situation économique se dégrade, et dans le contexte prérévolutionnaire, Joseph Delaville-Leroulx devient le leader du lobby négociant. Il est élu député aux États généraux pour obtenir l'abolition du monopole de la troisième compagnie et de la franchise du port, jugés responsables de la crise. Il reprend ses activités à Lorient mais se trouve sous la menace du gouvernement montagnard en 1794, avant de s'engager, après le coup d'état de Brumaire, dans une nouvelle carrière politique de sénateur sous le Consulat.

\section{ABSTRACT}

This article presents the successful career of a merchant, broker, and consignee integrated in dense trading, financial and political networks. Based in Ghent during the American war, after an apprenticeship in Amsterdam, Joseph DelavilleLeroulx migrated to the port of Lorient, the gateway to India and America. With the economic decline, he became the merchant lobby leader in the pre-Revolutionary context. But it was as member of the Constituent assembly for Lorient that he was able to push for the abolition of the monopoly of the third Indian company and of the harbour franchise, that were seen as being responsible for the crisis. Joseph Delaville-Leroulx resumed his activities in Lorient but, under threat from the government in 1794, he began a new political career as a Consulate senator after the coup of 18 Brumaire. 